\title{
Review of John B. Davis's Individuals and identity in economics. Cambridge (UK): Cambridge University Press, 2011, 270pp.
}

\author{
MIRIAM TESCHL \\ University of Vienna
}

John Davis has written this book because individuals are important. This is obvious, some will say. But not necessarily to economists, says Davis. Equipped with a respectable knowledge of relevant psychological, sociological, and philosophical theories, Davis examines in depth various representations of the individual in economics. He presents a useful, insightful and interesting picture of the various influences from other social sciences on the current characterisation of individuals that may be considered as a recent history of the representation of the economic agent. Davis also proposes other theories from philosophy and the social sciences that economists should incorporate to pay justice to what individuals are. He thus continues an analysis of the economic agent that he started in his previous book (Davis 2003). Whereas in his first book he was primarily concerned with explaining his methodology and considering what he calls "orthodox" and "heterodox" representations of the economic agent, this time he is focusing on what may be called "mainstream" representations of the individual, that is, the different visions and versions of individuals that can be encountered these days in any major economics journal. ${ }^{1}$

Central to Davis's methodology is the analysis of the representation of individuals in terms of two ontological criteria from the philosophical literature about personal identity: individuation and re-identification. These criteria stand for two different bounds: a lower bound-subpersonal-and an upper bound-supra-personal. The lower bound or identification criterion considers the question of whether the individual is a unique and single being that is not fragmented into multiple selves. The upper bound or re-identification criterion concerns the distinction between the individual and society, i.e., how much the individual is an independent and autonomous being and how much he or she is influenced or even determined by the "social". It determines whether

\footnotetext{
${ }^{1}$ For a detailed review of his first book see, e.g., Luchini and Teschl's (2005) review, as well as Davis's (2005) reply.
} 
individuals can be re-identified across change, that is, how a previously distinguished individual can be recognised as the selfsame individual at a later time and after various things about them have changed, especially when change means that they share characteristics with others.

Davis's ultimate aim, however, is to introduce his own conception of the individual. The book is thus arranged in such a way that he presents economics accounts of the individual in a spectrum from those that fit the least to those that fit the most with his understanding. While a legitimate way of organising one's own book, it raises some methodological questions. Without wanting to incite a full-blown debate on value-free (social) science, let us remark that the upshot of Davis's book is to present the 'correct' way of seeing individuals and then to discuss the shortcomings of other models with respect to his view of individuals. Of course, Davis claims that his view of individuals satisfies the two identity criteria-individuation and re-identification-whereas other models do not always do so, and he is in that sense complying with two objective philosophical criteria. But the point is that other models do not necessarily have in mind the question of what individuals are, but rather how individuals make choices. Moreover, Davis only provides an extended outline of his views without trying to engage in any formal representations, although the objects of many of his discussions are formal models, where reality is necessarily stripped down to the essential elements and presented as stylised facts. For the greatest part of the book, the latter are associated with giving an account of things where individuals do not matter, while Davis's verbal account does of course present individuals in a way in which they do matter. One cannot read this book without thinking at times of a swinging moral hammer. ${ }^{2}$

After an introductory chapter dedicated to the standard representation of Homo economicus and its limits the book is divided into three sections, named "Atomism revised", "Interaction", and "Socially embedded individuals". These sections analyse models based on insights from behavioural and experimental economics, social interaction models, and other more sociologically and philosophically

\footnotetext{
${ }^{2}$ Davis's closing sentences summarise this well: "It seems that the history we have inherited could well have told us that individuals do not count in this world and that only "higher" causes matter. This book presupposes just the opposite and asks that it be taken as central to economics and economic life" (p. 235).
} 
inspired accounts, and they end with considerations about justice and democracy.

The introduction sets out the groundwork and examines the representation of the typical Homo economicus who is provided with a given and stable preference ordering. Two main things are to be said here. One is that Davis considers this to be a circular account of individuals. Preferences do not explain what individuals are, because preferences presuppose individuals (p. 7). I interpret this to mean that individuals have preferences, but cannot be considered to be preferences. Second, Davis claims that individuals are taken to have their "own" private preferences (p. 7), which is a purely subjective account of the individual that is absolutely "unsupportable" (p. 222). Any account of individuals based on privacy and subjectivity is wrong and cannot explain individuals. Individuals are more than atomistic, totally autonomous and purely private beings. Individuals are not simply born with given and stable preferences. Instead their preferences (or rather 'capabilities' as Davis later argues) are actively and reflectively developed and modified throughout their socially embedded lives. The following three parts of the book lead step by step to this conclusion.

Part one starts with an account of what Davis calls "new" behavioural economics, which tries to make Homo economicus more psychologically realistic. Davis analyses Tversky and Kahneman's prospect theory and explains that a different representation of rationality than that of the standard Homo economicus also entails a different account of individuals. However, for Davis, prospect theory fails to take account of the sub-personal bound and is thus unable to represent the economic agent as a single individual. Prospect theory is about reference points that change over time, i.e., it is about context. Thus, "[c]hanges in context [...] disconnect the different stages of individuals from one another and prevent us from saying that those stages all belong to the same individual" (p. 35). The elimination of the sub-personal bound is actually a problem not only for prospect theory, but for any model that does not go far enough beyond the standard Homo economicus representation in terms of a utility function. It is even worse when preference reversals are observed. Here, description invariance (the framing effect) and procedure invariance (the elicitation effect) are violated. This research shows that preferences are constructed when needed, and are not pre-given. In this case, no utility function can represent those preferences and "there appears to be no 
obvious basis for talking about individuals as distinct beings whatsoever, much less reidentifying them in any way" (p. 44). It is basically a no-self approach.

Davis then moves on to consider Bénabou and Tirole's models of self-confidence and self-regulation. Different time-slices or different selves play non-cooperative games with each other to maintain or modify a particular level of self-confidence. They represent Homo sapiens and no longer Homo economicus because they lack hyperrational characteristics typically associated with Homo economicus: perfect self-knowledge, willpower, and recall. In these models, "[i]ndividuals [...] function collectively as single individuals who selfregulate themselves across their temporal selves by continually evaluating their successive selves' efforts to maintain and increase self-confidence" (p. 53). The problem with these models, however, is that self-control cannot be clearly separated from "other-control" (interpersonal influences), especially when Bénabou and Tirole extend their models to cover social interaction. There are then many different temporal selves trying to influence each other and there is no clear way to say which self belongs to whom.

Thaler and Sunstein are also concerned with Homo sapiens and propose some paternalistic yet libertarian interventions to help Homo sapiens make the right decisions. In this case, rational experts become important to provide the right "nudges" for individuals to make the best decisions for themselves. Self-control problems are solved at the level of society, which blurs the boundaries of the individual because rational experts act as surrogates on the individual's behalf.

Akerlof and Kranton's "identity economics" and the social preferences approach associated with economists such as Andreoni, Fehr, and Rabin are analysed next. The trademark of both accounts is that they introduce "sociality" into the utility function. This is not a good way of solving the connection between the individual and society, according to Davis. "[T]he strategy of internalizing social relationships within the utility function locates different social selves directly within individuals" (p. 70). Once again, the sub-personal bound is ineffective. For Davis, introducing social aspects into the utility function is not the correct way to give an appropriate representation of the individual because it individualises society and does not really get away from an atomistic conception. It should rather be the other way around-explaining the individual through his or her social interactions, 
thus socialising the individual-which is what Davis is concerned with in parts two and three of his book.

Part two starts with an analysis of the representation of the individual in game theory and experimental game theory, where individuals interact directly with each other. But it is still too involved with the atomistic conception of the individual. Davis then discusses different models such as Bacharach's view of the individual as a team and Ross's neuroeconomics based relational account. He then moves on to discuss Simon's influence on the representation of the individual via his conception of ecological rationality, which Davis calls the "old" behavioural economics. He also considers extensions of Simon's view, which Davis sees in Vernon Smith as well as in Binmore's evolutionary models and explanations. The crucial feature of these later contributions is that individuals are no longer endowed with affective preferences only, but (also) with some crucial abilities. Simon, for example, introduces important dynamic environmental adaptation mechanisms and powers; Binmore discusses learning processes as well as people's ability to empathise with others.

Part three becomes ever more philosophical. It starts by explaining Sen's capability approach and sets out to consider individuals as particular collections of capabilities, i.e., in terms of the beings and doings they have access to. Davis then discusses Pierre Livet's dynamic identity model of an individual, represented in terms of capabilities, who is changing over time. He also discusses two philosophical narrative identity approaches (Schechtman's and Dennett's).

All this serves to introduce Davis's own idea of the individual having a special personal identity capability, "interpreted as a capability for maintaining and developing an account of oneself in changing interactions with others" (p. 188). This capability is indeed crucial in order to account for a unified and single self; otherwise the individual would be merely a collection of capabilities, or a collection of selves based on his or her different social identities.

Davis then returns for one last time to economics to discuss two dynamic models of endogenous identity formation by looking at work on the co-evolution of individuals and social groups (Horst, Kirman, and Teschl 2007) and the emergence and persistence of racial identity norms (Darity, Mason, and Stewart 2006). Davis criticises these models for the unattractive result of the former (the equilibrium gives a weak personal identity over time, and thus more a multiple selves outcome than a 
unified single being) ${ }^{3}$ and the unattractive assumption of the latter (of encountering just one social/racial identity at a time) and moves on to his own view of the individual.

So what is this view? Davis bases his view on a capability conception of the individual and explains identity formation and change over time in terms of people's ability to develop their capabilities over time-a capability in itself, though a second-order one (a concept borrowed from Livet). This evolution and development of capabilities occurs through social interaction in society. Conflict is important here: different capabilities arise out of different social identities, but it is the conflicts between identities that generate the need to engage in self-organising processes.

Social identity has two aspects for individuals. One is relational and concerns an individual's engagement with others from a particular position or role that they occupy using first-person, i.e., self-reflexive, representations. The other is categorical and concerns the collective aspect of their identity, assessed from a third-person perspective. Over their lifetimes, individuals keep narrative accounts of themselves, which is a way to reflect on conflicts that their social identities may create, and this engagement and self-examination is what constitutes their personal identities. Indeed, personal identity is an evolving narrative, but it does not necessarily have to be a single, continuous story. It is rather a succession of ongoing conflict-solving discursive accounts, which also help the individual reflect upon the past and project themselves into the future. It is a way of being influenced by and influencing the social structure in which the individual evolves. The individual is thus socially embedded, and yet each self-narrative is highly individualised.

Davis closes his book with some considerations on economic policy, democracy and justice. It is an important topic as the standard representation of individuals in terms of preferences has been replaced by a more sophisticated account and hence Pareto efficiency evaluations are no longer applicable. While Davis argues that public discussion and value pluralism are important issues, he does not go very much beyond

\footnotetext{
${ }^{3}$ Being a co-author of this paper (Horst, et al. 2007), I allow myself to add an aspect not mentioned in Davis's analysis, namely that while he correctly summarises the equilibrium condition of our model, it says nothing about whether this equilibrium will ever be attained. This means that in off-equilibrium situations, personal identity is more important and the individual is not simply a set of multiple selves. This feature is actually one of the interesting aspects of the model.
} 
what Sen himself says about justice in terms of capabilities. Sen is against the "transcendental" approach to justice (Sen 2009), that is, an approach that sets out to clearly define what justice is. For Sen, this is much too contentious; he prefers a "comparative" approach that concentrates on ranking different social states as more or less just, but which does not necessarily have in mind to determine once and for all the form of the perfectly just society. It seems that Davis fully endorses this view, but he is then of course open to the same criticism that Sen faces, namely the indeterminacy in the evaluation of justice (see, e.g., Pogge 2010). How do we rank different people with different capability developments vis-à-vis each other? On what capability basis should we redistribute? What is the right trade-off between different capability developments and thus identities? While it might be argued that Davis contributes to the capability literature by presenting a dynamic capability view of the person, an aspect that could be considered to be missing in Sen's writing, he does not help solve these long-standing and important questions.

We could also see it from a different perspective. Davis and Sen propose the same vision of justice. Sen has arrived there by a meticulous study of other theories of justice such as utilitarianism and the Rawlsian justice as fairness approach (e.g., Sen 1999; and 2009). His starting point was the question of what it is that individuals have reason to value and thus to consider the appropriate space of justice. For him, this could not be, for example, pleasure or desire fulfilment as utilitarian-based justice accounts suppose, or any index of primary goods such as Rawls might suggest. Davis arrives there through his identity account of individuals. The question then is what is the added value of Davis's proposition? If we find out what individuals have reason to value, do we still need an identity account of them? Of course, these two approaches could go hand in hand-an identity account of individuals could tell us what they have reason to value-but this link would need to be explained and presented in much more detail.

This leads me to my final comment. Davis thinks that once all people have attained or have the opportunity to be provided with their basic and essential capabilities, they will then develop their own personal identities based on a multitude of different motivations and become heterogeneous people. He thinks that neoclassical economics has taken account of this by assuming differences in tastes. But, writes Davis, "differences in people between any point in time are not the same 
thing as differences in their pathways of development" (p. 190). Consequently, Davis thinks that "economics will need to say much more about the increasingly complex character of individuality if it is to explain the evolving nature of economic life" (p. 190). But is this the case? This would suggest that any choice theoretic model would need to incorporate a dynamic identity model to be able to understand people's choices. But choices are, in fine, made at a particular point in time. And even if we consider choices over time, we may still (simply) reflect upon some consistency requirements the individual should be complying with. That is, standard consistency axioms such as Sen's properties $\alpha$ and $\beta$, or the weak axiom of revealed preferences, have been criticised in the past. Indeed, Sen himself has argued that consistency without any external reference is too restrictive to say anything about rationality (e.g., Sen 1993). According to Davis, any rationality account is directly linked with a particular representation of the individual. Hence, if we need a more complex view of individuals, then it may be interesting to engage in research about identity consistency axioms that allow people to make changes over time and to develop their own capabilities and yet be fully rational. Hence, the idea would be to figure out what "identity consistent" choices are.

To conclude, Davis has presented a very stimulating philosophical account of identity. What is still missing from both this and his previous book is an explanation of what it means for economists in practical terms. That would certainly be a good project for a third book.

\section{REFERENCES}

Darity, William Jr., Patrick Mason, and James Stewart. 2006. The economics of identity: the origin and persistence of racial identity norms. Journal of Economic Behavior and Organization, 60 (3): 283-305.

Davis, John B. 2003. The theory of the individual in economics: identity and value. London: Routledge.

Davis, John B. 2005. Réponse à Luchini et Teschl. Revue Ethique et Economique/Ethics and Economics, 3 (1). http://hdl.handle.net/1866/3329 (accessed 20 October 2011).

Horst, Ulrich, Alan Kirman, and Miriam Teschl. 2007. Changing identity: the emergence of social groups. Economics Working Papers No. 0078. Institute for Advanced Study, School of Social Science, Princeton, NJ.

Luchini, Stéphane, and Miriam Teschl. 2005. Is there personal identity in economics? Revue Ethique et Economique/Ethics and Economics, 3 (1). http://hdl.handle.net/1866/3328 (accessed 20 October 2011).

Pogge, Thomas. 2010. A critique of the capability approach. In Measuring justice: primary goods and capabilities, eds. Harry Brighouse, and Ingrid Robeyns. Cambridge: Cambridge University Press, 17-60. 
Sen, Amartya. 1993. Internal consistency of choice. Econometrica, 61 (3): 495-521. Sen, Amartya. 1999. Development as freedom. New York: Alfred A. Knopf. Sen, Amartya. 2009. The idea of justice. London: Penguin Books.

Miriam Teschl is a Hertha Firnberg research fellow at the department of economics at the University of Vienna. She was previously fellow and director of studies at Robinson College and Homerton College at the University of Cambridge (UK). She completed her $\mathrm{PhD}$ in philosophy and economics at universities in France and the UK on the topic of the "Identity of the economic agent". She now works on the rationality of choice with a focus on conflictual choices, distributive justice, and the emergence of negative social preferences.

Contact e-mail: <miriam.teschl@univie.ac.at> 